\title{
In vitro antimalarial activity of Calophyllum bicolor and hemozoin crystals observed by Transmission Electron Microscope (TEM)
}

\author{
Jamilah Abbas* \\ Research Center for Chemistry, Indonesian Institute of Sciences (LIPI) PUSPIPTEK, Serpong, Indonesia
}

\begin{abstract}
Objective: In continuation of our antimalarial candidate drug discovery program on Indonesia medicinal plants especially from stem bark of Calophyllum bicolor. Metode: We extracted of bioactive crude extract with hexane, acetone and methanol from stem bark of Calophyllum bicolor and evaluated their antimalarial activity by using parasite Plasmodium falciparum in vitro. Results: Methanol fraction showed most active and potent antimalarial activity dose dependent in in vitro experiments with $\mathrm{IC}_{50}=0.52$ $\mathrm{ppb}$, and hexane fraction showed moderate antimalarial activity, but dose not dependent, while acetone fraction have not antimalarial activity. TEM (Trasmission Electron Microscopy) analysis confirmed a remarkable reduction of hemozoin in the presence of the bioactive fraction. Conclusion: The results suggest that the antimalarial activity of Calophyllum bicolor is due, methanol fraction showed the best in vitro antimalarial activity then another fraction.
\end{abstract}

Keywords: Calophyllum bicolor, Plasmodium falciparum, in-vitro, TEM (Transmition Electron Mecroscope)

\section{Introduction}

Malaria is a serious parasitic disease transmitted by the bites of the female Anopheles mosquites, there are 4 species of plasmodium, e.i. Plasmodium falciparum, $P$ vivax, $P$ malaria, and $P$ ovale, which $P$ falciparum the most lethal $[1,2,3]$. Parasites belonging to Phyllum protozoa and genus Plasmodium are the most important causal pathogens and cause several human infection with globally massive impact[4]. Malaria remain one of the most significant world-wide public health problem, especially in tropical and subtropical regions [5]. Malaria is endemic to 90 counties world health and effects nearly $40 \%$ of the the world's population. Malaria is responsible for the death of 1-2 million each year with more than $90 \%$ of cases found in sub Saharan Africa and $\geq 1$ case per 1000 population, and $80 \%$ of such cases are concentrated in 13 cauntires, over half in Negeria, Congo, Ethiopia, Tanzania and Kenya. [6, 7, 1]. Nigeria accounts for a quarter of all malaria cases in Africa. In the southern part of the country, transmission occurs all year round while in the north it is more seasonal [1].

One major virulence factor of this parasite is the highly variant $P$. falciparum erythrocyte membrane protein-1 (PfEMP) family. The malaria parasite in its blood stage is a voracious consumer of the globin component of hemoglobin, which causes the release of copious amounts $(>4000 \mathrm{mM})$ of toxic heme. Proteolysis of hemoglobin yields amino acid for protein synthesis as well as toxic heme. However, the parasite withstands heme toxicity by employing efficeinets mechanisms of heme detoxification. The conversion of heme to the relative benign heme polymer, hemozoin, is achieved by a process akin to template-mediated biomineralization. Templates for heme polymerization include performance hemozoin, histidin rich protein, and lipid or parasite cannot enzymatically cleave the porphyrin ring, heme is'detoxified' by conversion to an insolubly polymer, hemozoin $[8,9]$.

The emergence and rapid spread of multidrugresistant strains of Plasmodium, particularly Plasmodium falciparum has led to serious problem for prophylaxis and treatment malaria, which becomes more difficult and limits the ability to control this disease and also limits the choice of drugs used. This has been identified as the current primary cause of control failure, this highlights the need to develop quickly more effective and less toxic new antimalarial drugs with different mechanism of action [9. 10]. It has been suggested that hemozoin formation is inhibited by the extract Calophyllum. 


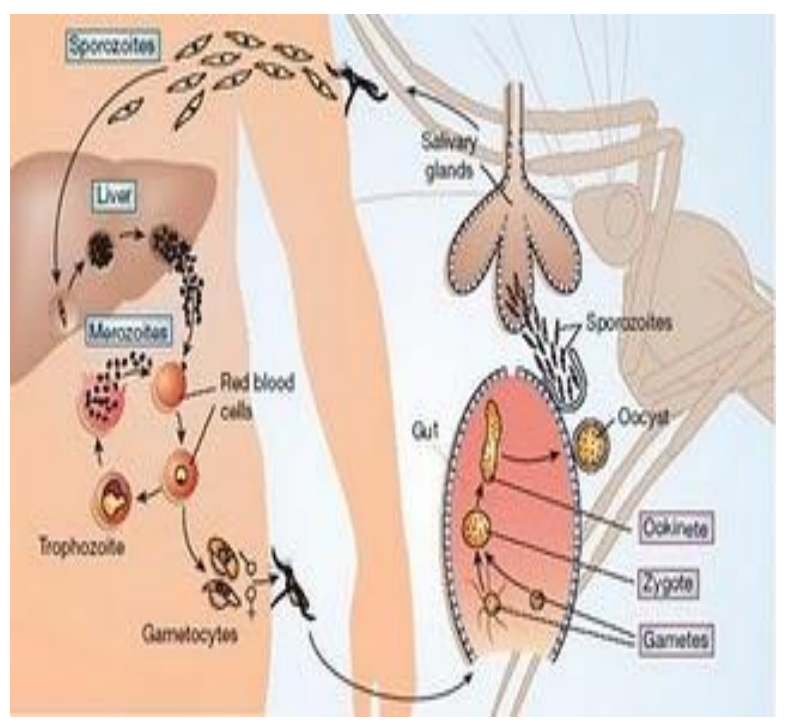

Fig 1. Live cycleof P.falciparum parasite

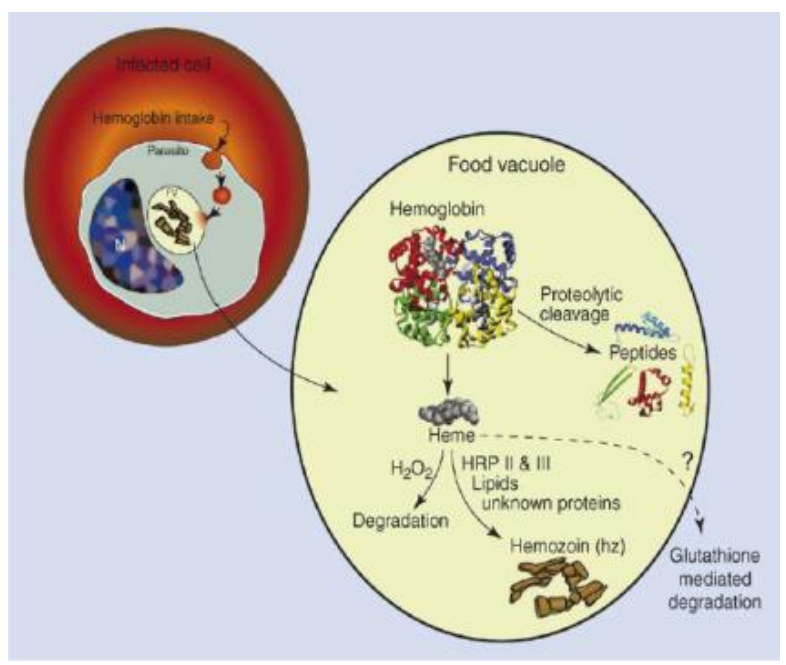

Fig 2. Heme degradation and hemozoin formatoion

Transmission electron microscope (TEM). TEM is one of type of electron microscope that has three essential systems: (1) an electron gun, generating the electron beam, and the condenser system, which focusing the beam onto the object, (2) the image-producing system, consisting of the objective lens, movable specimen stage, and intermediate and projector lenses, focusing the electrons passing through the specimen to form a real, highly magnified image, and (3) the image-recording system, converting the electron image toward some form perceptible to the human eye. The image-recording system usually covers of a fluorescent screen for showing and focusing the image and a digital camera for permanent records. Bisides,on, a vacuum system, consisting of pumps and their associated gauges and valves, and power supplies are needed.see Figure 4 [11]

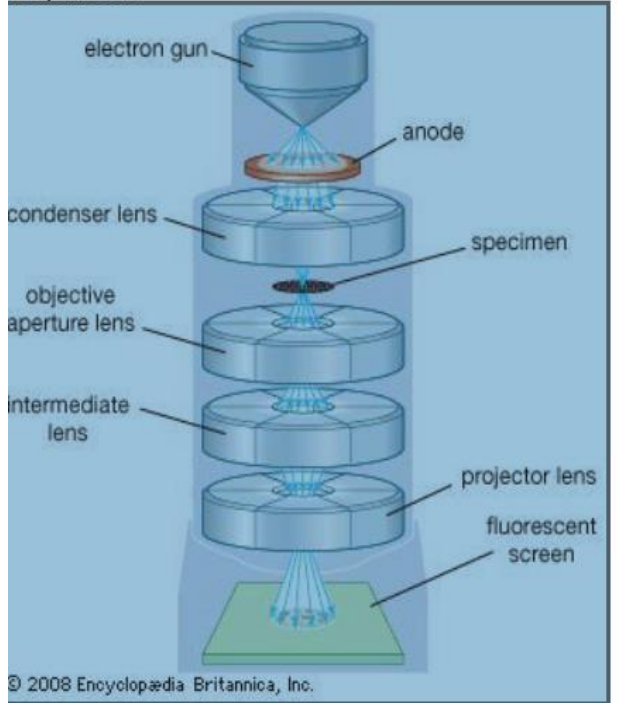

Fig 3. Transmission electron microscope (TEM)

\section{Material and Methods}

\subsection{Material}

\subsubsection{General experimental procedures}

TEM (transmission electrone microscope), maserator, evaporator,UV lamp.

\subsubsection{Sample}

C. bicolor P.F Stevent $(2.858 \mathrm{~kg})$ and C. europhyllum $(1.555 \mathrm{~kg})$ were collected in Bulungan, Kalimantan Island, in Indonesia. The plant were determined by staff from Herbarium Research Centre for Biology - LIPI and voucher specimen was deposited at the Herbarium Research Centre for Biology-LIPI. Indonesia.

\subsubsection{Chemical material}

RPMI media and glutamin were obtained from Nissui, $\mathrm{NaHCO}_{3}$ was purchased from E. Merck. Silica gel 200300 mesh, TLC plates were purchased from E. Merck and all organic solvent (methanol, hexane, $\mathrm{CH}_{2} \mathrm{Cl}_{2}$, ethyl acetate) were purchased from local market. RPMI media contain $2,5 \mu \mathrm{g} / \mathrm{mL}$ gentamicin, $50 \mu \mathrm{g} / \mathrm{mL}$ hypoxanthin, $25 \mathrm{mM}$ buffer HEPES (N-2-hydroxyethylpiperazine- $N$ '2- ethanne sulfonic acid, (GibcoBRL), $25 \mathrm{mM}$ natrium bikarbonat, $10 \%$ human serum $\mathrm{AB}+, 5 \%$ hematokrit, human erythrocytes, and chloroquin was used as a positif control. DMSO were used to dilute of the samples

\subsection{Methods}

\subsubsection{Extraction}

The air-dired $C$. bicolor P.F Stevent $(2.858 \mathrm{~kg})$ and $C$. europhyllum Lauter $(2,555 \mathrm{~kg})$ were successively extracted with $n$-hexane, acetone and methanol at room 
temperature for 4 day and such was repeated three times, the solvent were evaporated under reduced pressure to give hexane extract. The residue was extract successively with acetone (10 lt $\times 3$ ) and methanol (10 lt x 3), then acetone and methanol were evaporated under reduced pressure to give a acetone and methanol extracts.

\subsubsection{Antimalarial test}

Erythrocytes infected with Plasmodium falciparum strain 3D7, from cultures obtained using the method Trager and Janson up to density of parasites $2 \%$, were suspended in complete culture medium at a hematocrit of $5 \%$. The suspension parasite was distributed in 96-well micro titer plates $(200 \mu \mathrm{l}$ per well). To determine the antimalarial activity against plasmodium falciparum, each extract $(5 \mathrm{mg})$ was first dissolved in dimethyl sulfoxide $(100 \mu 1$ DMSO mix with vortek until all samples dilution completely, and then diluted with completed medium (RPMI) to obtain the desired concentration ( $5 \mathrm{mg}$ x $10^{-2} \mu 1$ until $\left.\times 5 \mathrm{mg} \mathrm{x} 10^{-9} \mu \mathrm{l}\right)$, total volume in each well plate are $1 \mathrm{ml}$ ) and cloroquin was used as a positive control.

Compounds were tested in duplicate in $2 \%$ parasitemia cultures mostly at ring stage. For each assay, a parasite culture was incubated with the compound at 37 ${ }^{\circ} \mathrm{C}$ for $48 \mathrm{~h}$ in $5 \% \mathrm{CO}_{2}$ at $95 \%$ relative humidity and frozen until the biochemical assay could be run. After 48 hours of incubation ach well was harvested to a glass were then fixation by methanol, also added Geimsa reagent.

Concentration of extract required to inhibit $50 \%$ parasite growth $\left(\mathrm{IC}_{50}\right)$ was determined by computer. Parasit amount was monitoring by microscope, and computer by linear program Sigma-plot $\left(\mathrm{IC}_{50}\right)$ was used for calculated of $\mathrm{IC}_{50}$. The antimalarial activity was expressed as the $\mathrm{IC}_{50}$ value (ppm), which was defined as the concentration of extract required to inhibit $50 \%$ parasite growth after 48 -h incubation at $38^{\circ} \mathrm{C}$.

\subsubsection{TEM (Transmission electron microscope)}

Brief, small amount of extract were placed on the grid (formvar carbon coated $\mathrm{Cu}$ messed 300), at the acceleration voltage of $80 \mathrm{kV}$, using Zeiss. Model EM 10c (Jeol Japan). In addition, the apparatus was used for imaging at two different scales 24 and $30 \mathrm{~nm}$. in-situ and after isolation was used for detect hemozoin

\subsubsection{Flow chart of methode}

Separation sample

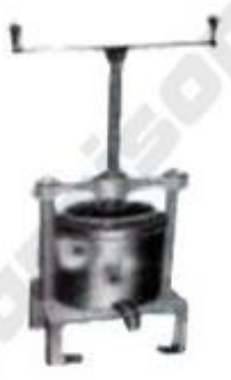

Maseration

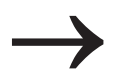

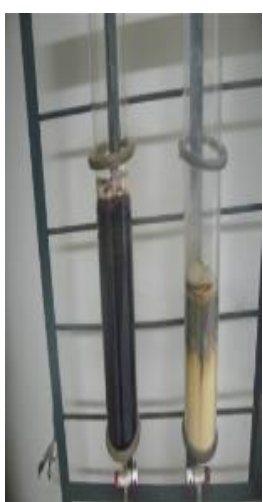

Separation

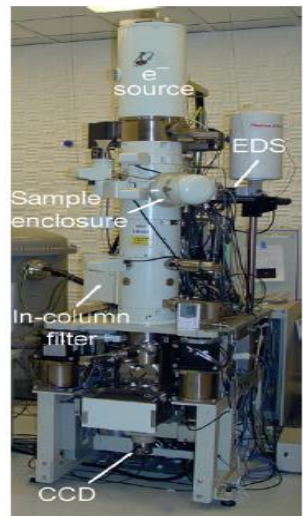

Fig. 4 . Flow chart of isolation and TEM analysis 


\section{Results and Discussion}

\subsection{TEM result}

\subsubsection{TEM analysis of the fraction containing bioactive material showed significan hemozoin reduction.}

In TEM, fixed-illumination mode, individual spectra are obtained from whichever area of the sample is illuminated. To control the sampling volume, the microscopist converges the beam to illuminate only the region of interest uses postspecimen apertures to select the divergence angle of electrons reaching the spectrometer. Because the sample and beam are fixed relative to each other, spectra, EDS and/or EELS, can be obtained in TEM mode

\subsubsection{TEM imaging- Produccing system.}

The specimen grid is conducted in a small holder in amoved specimen stage,. The objective lens is usually of short focsal length 1-5 mm (0.04-0.2 inch) and results a real intermediate image that is furher magnified by the projector lenses. A single projector lens will provide a range of magnification of $5: 1$. For practical reasons of image stability and brightness, the microscope is operated to give a final magnification of $1,000-250,000 \mathrm{x}$ on the sreen to show the hemozoin crystal.

Reduction of hemozoin crystal formation in the present of bioactive fraction had investigated by using TEM (Transmition Electrone Microscope) technich insitu and after isolation. The identification of spesific area of hemozoin an image, or pixels with specified characteristic,

To furher characterize the antimalarial activity of Calophyllum, methanol extract (from the late sate of hemozoin formation) in the present sample after 1 $\times 24 \mathrm{hr}$ incubation and in present sample after after $2 \times 24 \mathrm{hr}$ incubation were examined by TEM. There existed numerous hemozoin with diameter $1 \mu \mathrm{m}$ after $1 \times 24$ incubated, but there are not hemozoin after $2 \times 24 \mathrm{hr}$ incubation).

The transmission electron microscope (TEM) image in Figure 5 showed hemozoin crystal extracted from the sample previously used for the MO measurement. The typical length of the extracted hemozoin crystal range $500 \mathrm{~nm}$. For comparison., a TEM image of synthetic hemozoin crystal in our MO study, is showen in panel A and $\mathrm{B}$. The synthetic crystal have more elongated shape in typical length $500 \mathrm{~nm}$. Panel A and B display TEM images of intact infected erythrocytes in the schizont stage. Distinct component of the parasite and erythrocyte can be observed including the erhythrocyte membrane (EM), parasite membrane (PM). Food vacuole membrane (FVM), merozoite (M), hemoglobin transport vesicles (HbTV) knons (9K) and hemozoin (Hz).Figure 5 and Figure 6 .

\subsubsection{Figure from TEM results}

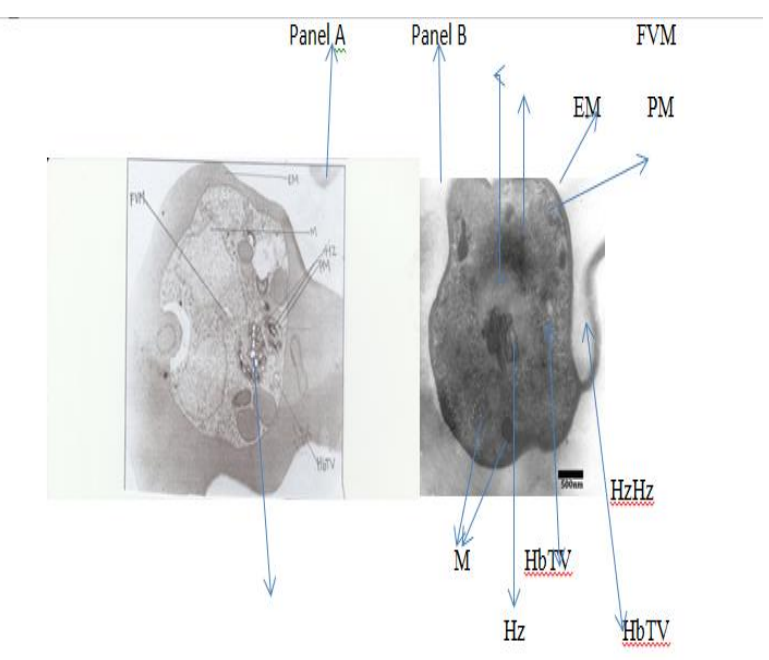

Fig 5. Hemozoin crystal showed in figure as white crystal after $1 \times 24$ incubattion

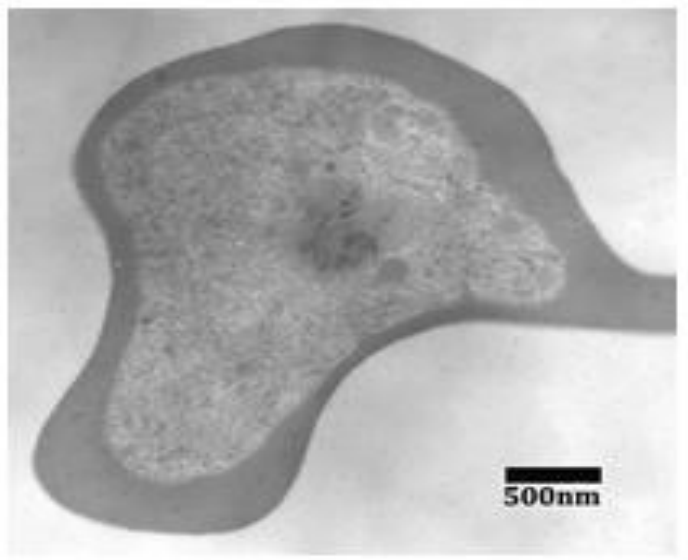

Fig 6. Hemozoin crystal have not showed in figure after $2 \times 24$ incubattion

\subsection{Sepration results}

The present investigation for antimalarial principles from C. bicolor has led to the finding of three fraction, e.i, hexane (208.29 g), acetone (413.62 g) and methanol $149.8 \mathrm{~g}$.

\subsection{Antimalarial activity results}

According to the previous paper [12] which it's explained that antimalarial activity of methanol fraction of $C$. bicolor have better than hexane fraction, and hexane fraction have better than acetone fraction while the acetone fraction have not antimalarial activity, these data showed in Figure 7. 


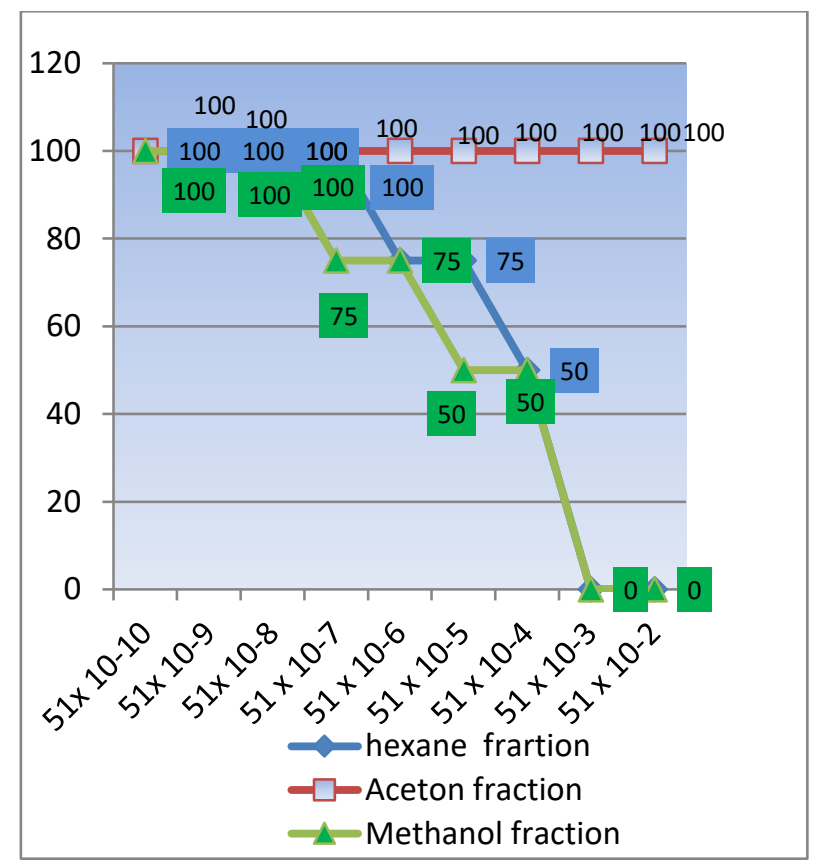

Fig 7. Grafik antimalarial activity of hexane,acetone and methanol fraction of $\mathrm{C}$ bicolor.

Antimalarial activity of the metanol fraction best compare hexane and acetone fraction, these methanol fraction are devided further into five sub fraction (e.i sub fraction $9: 1 ; 8: 2 ; 7: 3 ; 6: 4 ; 5: 5$. The data antimalrial activity explaned in Table 1

Table 1. Antimalarial activity of sub fraction methanol

\begin{tabular}{|c|c|c|c|c|c|}
\hline $\begin{array}{c}\text { DOSA } \\
\text { GE }\end{array}$ & $\begin{array}{c}\mathrm{C} . \mathrm{Bi} \\
\mathrm{MeOH} \\
9: 1\end{array}$ & $\begin{array}{c}\mathrm{C} . \mathrm{Bi} \\
\mathrm{MeOH} \\
8: 2\end{array}$ & $\begin{array}{c}\mathrm{C} . \mathrm{Bi} \\
\mathrm{MeOH} \\
7: 3\end{array}$ & $\begin{array}{c}\mathrm{C} . \mathrm{Bi} \\
\mathrm{MeOH} \\
6: 4\end{array}$ & $\begin{array}{c}\mathrm{C} . \mathrm{Bi} \\
\mathrm{MeOH} \\
5: 5\end{array}$ \\
\hline $1.00 \mathrm{E}-09$ & 83 & 145 & 65.2 & 111 & 100 \\
\hline $1.00 \mathrm{E}-08$ & 92 & 118 & 43.75 & 100 & 100 \\
\hline $1.00 \mathrm{E}-07$ & 92 & 136 & 43.75 & 133 & 127 \\
\hline $1.00 \mathrm{E}-06$ & 117 & 127 & 37.5 & 122 & 127 \\
\hline $1.00 \mathrm{E}-05$ & 141 & 136 & 31.25 & 100 & 127 \\
\hline $1.00 \mathrm{E}-04$ & $\mathbf{7 5}$ & 136 & 75 & 88 & 118 \\
\hline $1.00 \mathrm{E}-03$ & 83 & 127 & 62.5 & 122 & 81 \\
\hline $1.00 \mathrm{E}-02$ & 83 & 118 & 37.5 & 55 & 9 \\
\hline $1.00 \mathrm{E}-01$ & 16 & 18 & 31.25 & 0 & 0 \\
\hline
\end{tabular}

\section{Discussion}

The present investigation for antimalarial principal from methanol fraction of $C$. bicolor has led to the finding of five sub fraction e.i sub fration $\mathrm{MeOH} 9: 1 ; \mathrm{MeOH} 8: 2$; $\mathrm{MeOH} 7: 3$; MeOH $6: 4$ and MeOH 5 :5. Among the sub fraction which had weak-to-moderate antimalarial activities on $P$. falcioparum parasite. Antimalarial activities of sub fraction methanol e.i sub fraction $\mathrm{MeOH}$ $9: 1$; $\mathrm{MeOH} 8: 2$; $\mathrm{MeOH} 7: 3$; $\mathrm{MeOH} 6: 4$ and $\mathrm{MeOH}$ $5: 5$ were elustrated in Figure 8.9

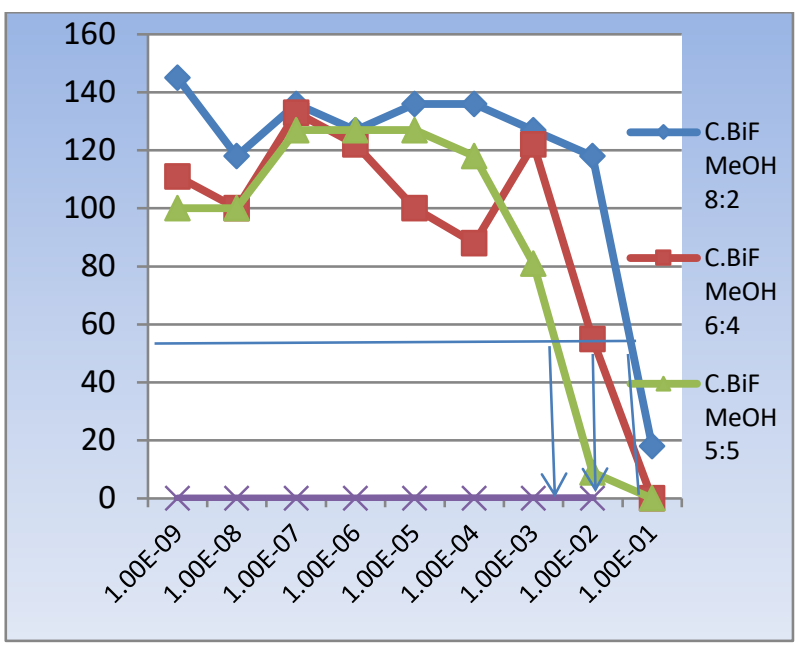

Fig 8. Antimalarial activity of sub fraction $\mathrm{MeOH} 8: 2 ; 6: 4$ and $5: 5$

Percentage of parasite $P$. falciparum growth versus sample concentration $\left(10^{-9}\right.$ to $\left.10^{-1} \mathrm{mg} / \mathrm{mL}\right)$ was observed. The increasing in sample concentration should decrease the parasite growth percentage. Increasing sample concentration from $10^{-9}$ to $10^{-8} \mathrm{mg} / \mathrm{mL}$ leads to a decrease the percentage of parasite growth from 145 to $111: 65.2$ to 43.75 and 111 to $100 \%$ for sub fraction $8: 2 ; 6: 4$ and $5: 5$ respectively.

Unfortunately,In the fact state that the increasing sample concentration from $10^{-8}$ to $10^{-7} \mathrm{mg} / \mathrm{mL}$ did not cause a decreasing percentage of parasite growth, this illustrates that the percentage decreasing parasite growth does not depend on the sample concentration (see Figure 8).

According to the Figure 8, we can calculated the $\mathrm{IC}_{50}$ of sub faction $\mathrm{MeOH} 8: 2 ; 6: 4$ and $5: 5$ samples are 50 $\times 10^{-1} \mathrm{mg} / \mathrm{mL}, \quad 50 \times 10^{-2} \mathrm{mg} / \mathrm{mL}$ and $50 \times 10^{-3} \mathrm{mg} / \mathrm{mL}$ respectively (equivalent $5000 \mathrm{ppm}, 500 \mathrm{ppm}$ and $50 \mathrm{ppm}$ respectively).

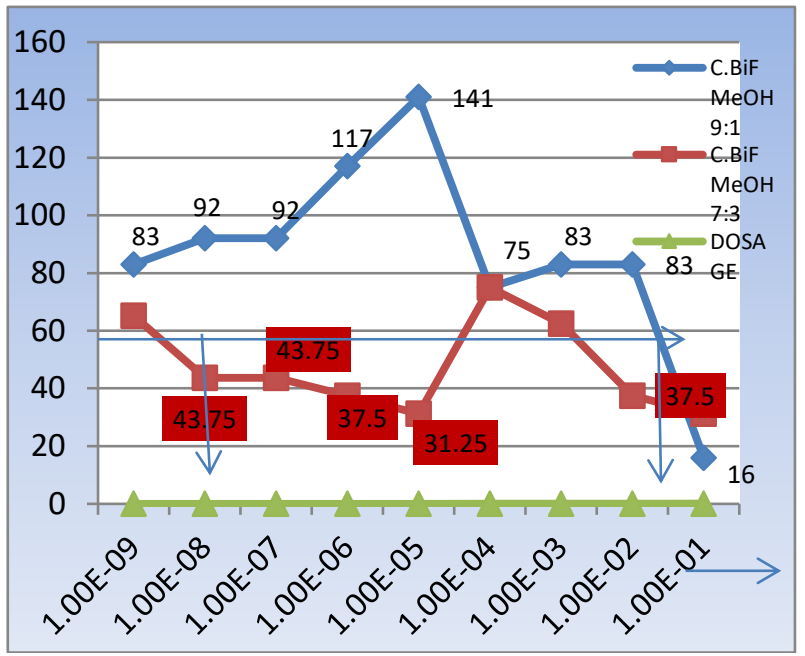

Fig 9. Antimalarial activity of sub fraction $\mathrm{MeOH} 9: 1$; and $7: 3$

The antimalarial activity of sub fraction 9: 1 and 7:3 are described in Figure 9. In case of sub fraction $7: 3$ sample, increasing the sample concentration from $10^{-9}$ to $10^{-8} ; 10^{-7}$ to $10^{6} ; 10^{-6}$ to $10^{-5} \mathrm{mg} / \mathrm{mL}$ leads to a decrease 
the percentage of parasite growth from 65.2 to $43.75 \%$ : 43.75 to 37.5 and 37.5 to $31.24 \%$ respectively. Unfortunately increasing sample concentration from $10^{-5}$ to $10^{-4} \mathrm{mg} / \mathrm{mL}$ did not cause a decreasing percentage of parasite growth.

According to the Figure 9, we can calculated the $\mathrm{IC}_{50}$ of sub faction $\mathrm{MeOH} 7: 3$ is $50 \times 10^{-8} \mathrm{mg} / \mathrm{mL}$ (equivalent $0.005 \mathrm{ppm}$ ), and $\mathrm{IC}_{50}$ of sub fraction $9: 1$ sample is $50 \mathrm{x}$ $10^{-2} \mathrm{mg} / \mathrm{mL}$ (equivalent $0.5 \mathrm{ppm}$ ).According to the Figure 8 and 9, conclution taht the sub fraction $\mathrm{MeOH}$ $7: 3$ is better as antimalarial compare to any another sub fraction.

One pure compound have isolated from the sub fraction of $C$. bicolor and have antimalarial activity with $\mathrm{IC}_{50}$ is $50 \times 10^{-2} \mathrm{mg} / \mathrm{mL}$ (equivalent is $500 \mathrm{ppm}$ ) (see Table 2 and Figure 10

Table 2. Antimalarial activity of isolate compound

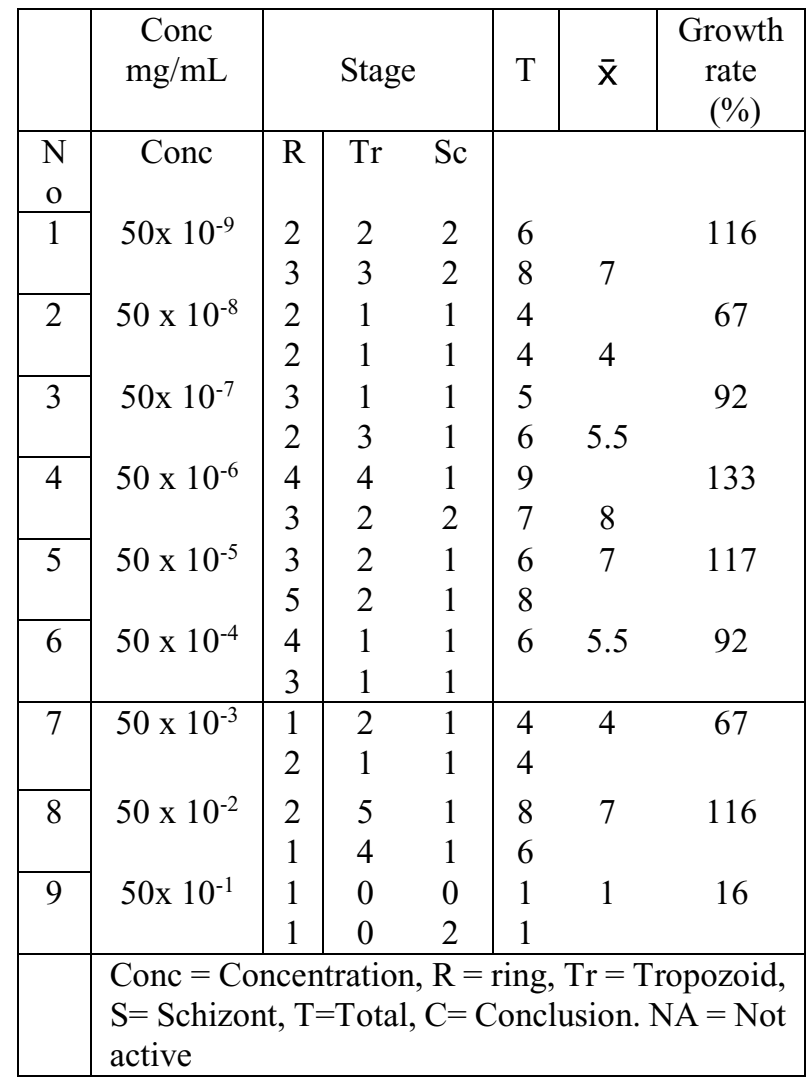

One pure compound have isolated as trepenoid from stem bark of C. bicolor. Triterpen as white powder. LC-MS (Figure 7) displayed a positive molecular ion paek at $\mathrm{m} / \mathrm{z}$ 387,86 $[\mathrm{M}+\mathrm{H}]^{+}$indicating a molecular formula $\mathrm{C}_{27} \mathrm{H}_{46} \mathrm{O}$.

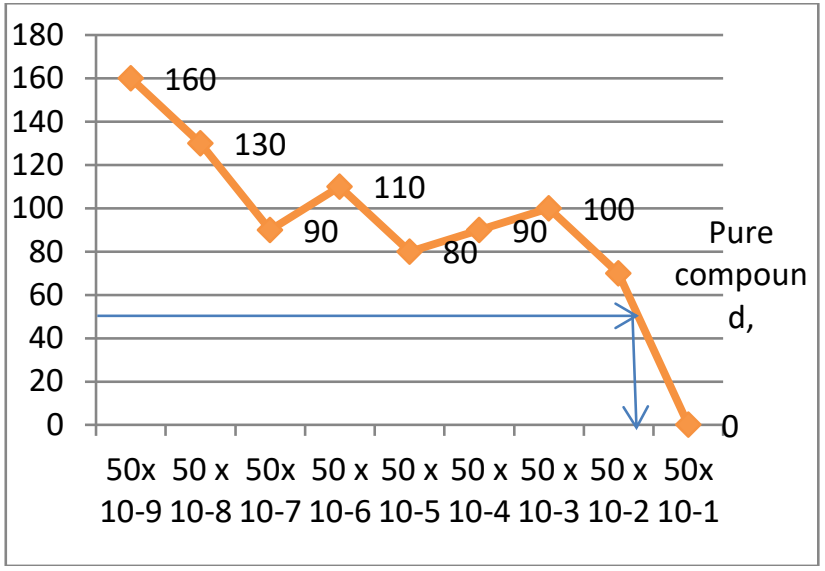

Fig 10. Antimalarial activity of pure isolate compound

Pure isolate compound have tested by using TLC. The TLC result saw single spot ( Figure 11).

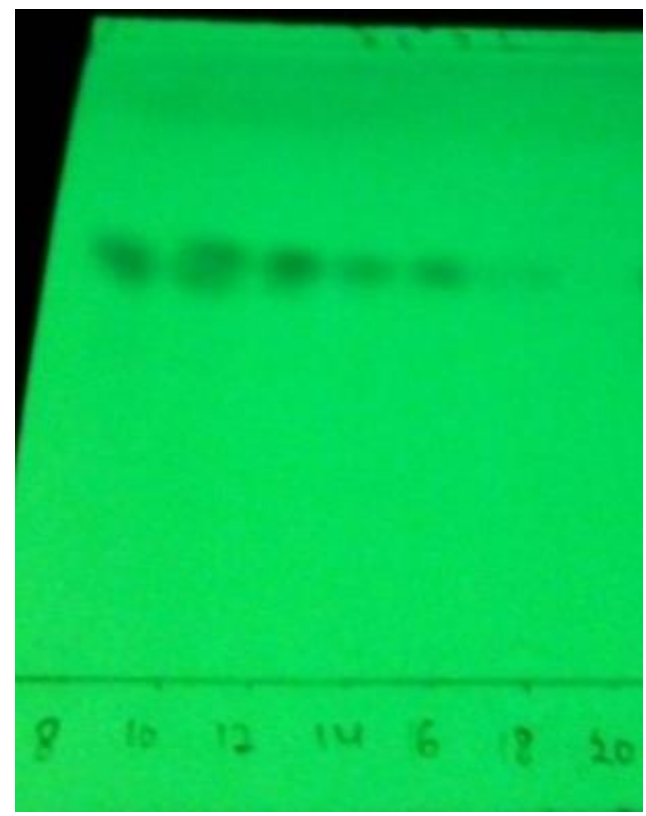

Fig 11. TLC spot of pure isolate compound

One compound have isolated as trepenoid from stem bark of C. bicolor. Triterpen as white powder. LC-MS (Figure 12) displayed a positive molecular ion paek at $\mathrm{m} / \mathrm{z}$ $387,86[\mathrm{M}+\mathrm{H}]^{+}$indicating a molecular formula $\mathrm{C}_{27} \mathrm{H}_{46} \mathrm{O}$.

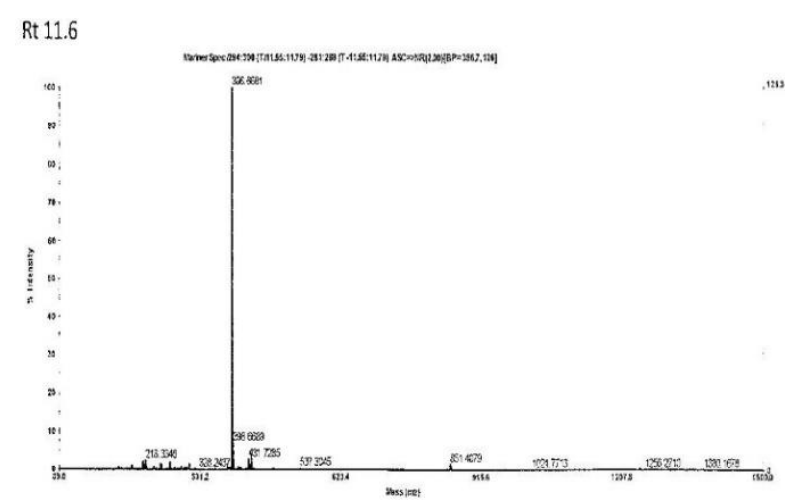

Fig 12. LC-MS spectrum of pure isolate compound

Isolated compound give typical triterpen IR absorption at $3210-3550 \mathrm{~cm}^{-1}(\mathrm{OH}), 2930(\mathrm{sp} 3 / \mathrm{CH} 3$ 
aliphatic and $2864 \mathrm{~cm}^{-1} \mathrm{sp} 2 / \mathrm{CH}_{2}$ aliphatic), $1681(\mathrm{C}=\mathrm{C})$ $\mathrm{cm}-1$ and $1456 \mathrm{~cm}^{-1}$ as $\mathrm{CH}$ bending (Figure 13)

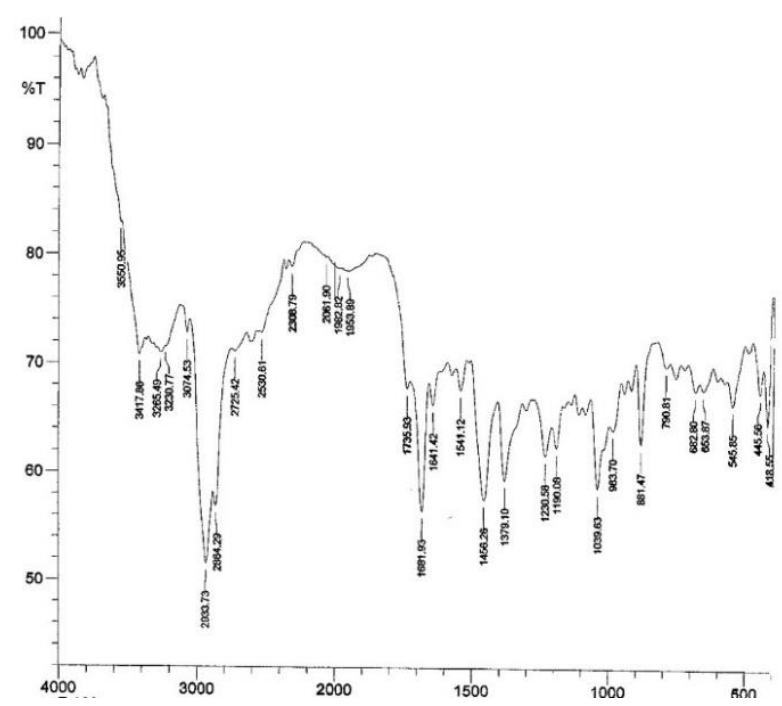

Fig 13. Infra Red spectrum of pure isolate compound

UV spectrum of pure isolate compoune was showed in figure 14. Maximum absorption were observed at wave length $233,5 \mathrm{~nm}$ as electron transition of $\pi$ to $\pi^{*}$ from $\mathrm{C}=\mathrm{C}$ group and wave length $295 \mathrm{~nm}$ as electron transition of $n-\pi^{*}$ from $\mathrm{OH}$ group.

1.000

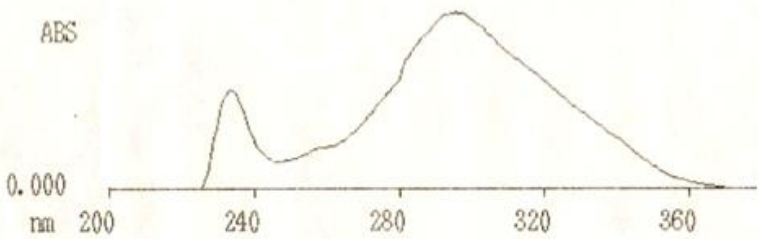

Fig 14. UV spectrum of pure isolate compound

The ${ }^{1} \mathrm{H}-\mathrm{NMR}$ spectrum revealed the presence of one hydroxyl proton doublet at $\delta_{\mathrm{H}} 12 \mathrm{ppm}(1 \mathrm{~s}, \mathrm{OH})$, one alyllic proton signal at $\delta_{\mathrm{H}} 4.72(\mathrm{dd}, 2 \mathrm{H}, \mathrm{J}=2.6$ and 4.56 $\mathrm{Hz}$ ) for $\mathrm{H}-21$ recpectively. There are 6 six methyls singlet signal at $\delta_{\mathrm{H}} 0,75 \mathrm{ppm} ; 0,85 \mathrm{ppm} ; \delta_{\mathrm{H}} 0,95 \mathrm{ppm} ; \delta_{\mathrm{H}} 0,96$ ppm; $\delta_{\mathrm{H}} 1,01 \mathrm{ppm}$ and $\delta_{\mathrm{H}} 1,7 \mathrm{ppm}\left(\mathrm{sp}_{3} \mathrm{CH}\right)$ (Figure 15)

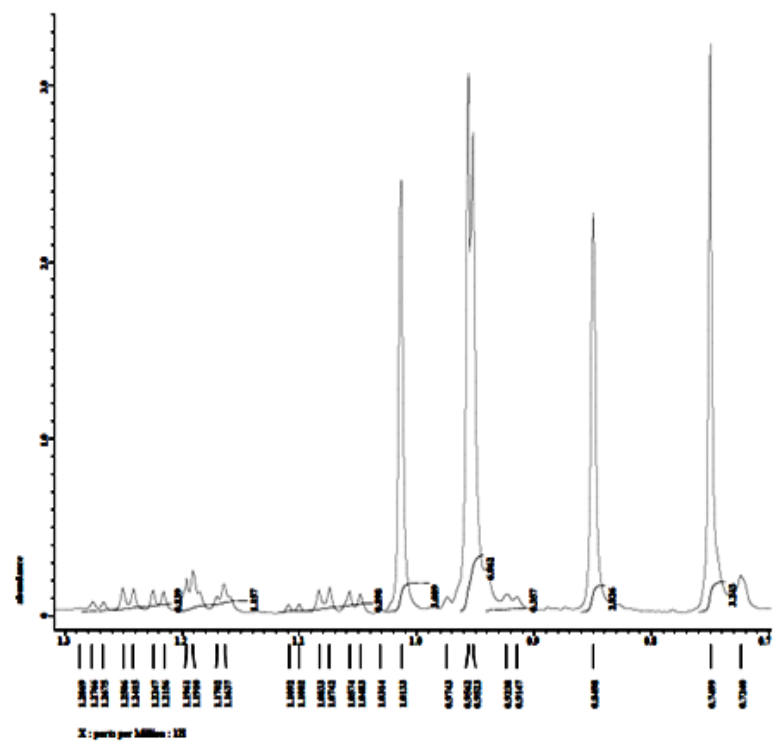

Fig 15. ${ }^{1} \mathrm{H}-\mathrm{NMRspectrum}$ of pure isolate compound

There are ten metilen $\left(\mathrm{CH}_{2}\right)$ signal at $\delta_{\mathrm{H}} 1,36 \mathrm{ppm} ; \delta_{\mathrm{H}}$ $1,56 \mathrm{ppm} ; \delta_{\mathrm{H}} 1,91 \mathrm{ppm} ; \delta_{\mathrm{H}} 1,30 \mathrm{ppm} ; \delta_{\mathrm{H}} 1,46 \mathrm{ppm} ; \delta_{\mathrm{H}}$ $1,43 \mathrm{ppm} ; \delta_{\mathrm{H}} 1,63 \mathrm{ppm} ; \delta_{\mathrm{H}} 1,51 \mathrm{ppm} ; \delta_{\mathrm{H}} 1,48 \mathrm{ppm} ; \delta_{\mathrm{H}}$ $3,05 \mathrm{ppm}$ and $\delta_{\mathrm{H}} 4,72 \mathrm{ppm}(2 \mathrm{H}, d d \mathrm{~J} 2,6 \& 4,92)$.

Signal at $\delta_{\mathrm{H}} 3,12 \mathrm{ppm}(1 \mathrm{H}, d d \mathrm{~J} 5,28 \& 11,65)$ is signal of mehine $(\mathrm{CH})$ at position $\mathrm{C}-3$ of triterpenoid compound, Isolate compound also have one hydroxil group at C-3. Unfortunately isolate compound have not signal at 6-8 ppm, these indicated that isolate compound have not aromatic proton.

There are six methine $(\mathrm{CH})$ signal at $\delta_{\mathrm{H}}, 3.12 \mathrm{ppm}$, $2,35 \mathrm{ppm}\left(1 \mathrm{H}, d d d \mathrm{~J} 3,25 ; 2,95, \delta_{\mathrm{H}} 2,24 \mathrm{ppm}, \delta_{\mathrm{H}} 1,18 \mathrm{ppm}\right.$ and $\delta_{\mathrm{H}} 1,08 \mathrm{ppm}, \mathrm{CH}$ signal will be explained in figure 16

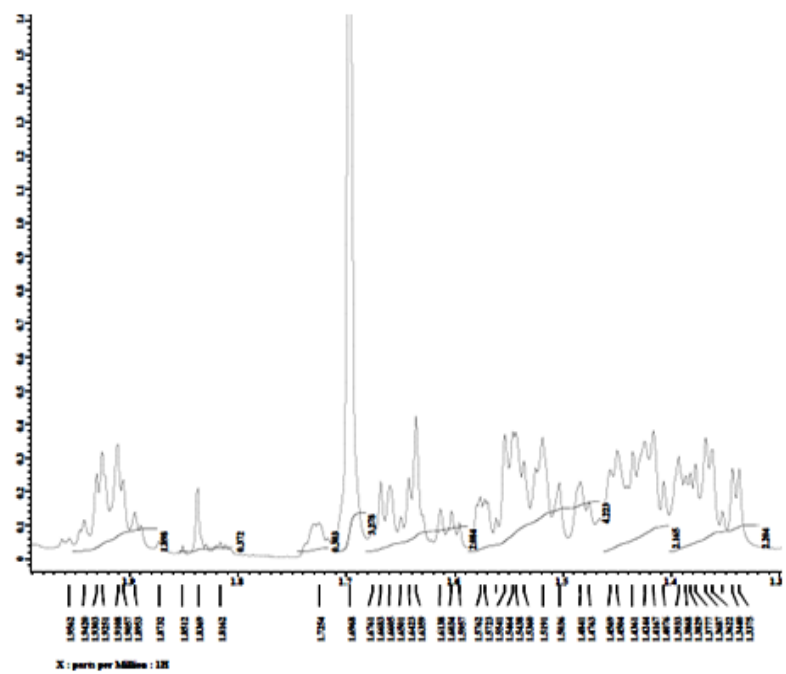

Fig 16. ${ }^{1} \mathrm{H}-\mathrm{NMR}$ spectrum of pure isolate compound

The ${ }^{13} \mathrm{C}-\mathrm{NMR}$ spectrum and DEPT experiment showed the presence 6 six methyl, ten methylene, six methine five quartener carbons at $\partial 39.6(\mathrm{C}-4), 56.4$ (C5), 39.1 (C-8), 39.7 (C-10) and 151.7 (C-21) respectively see Figure 17 


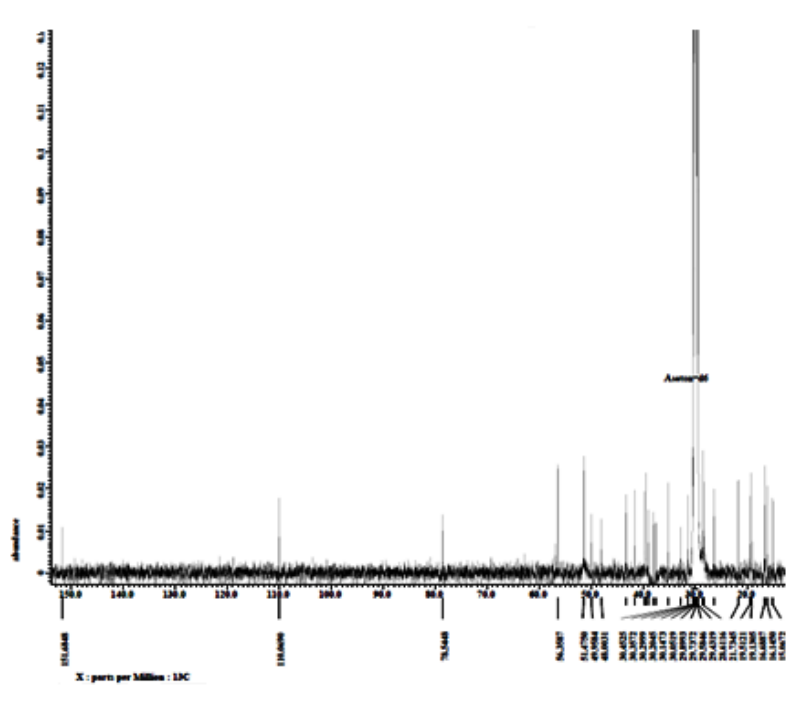

Fig 17. ${ }^{13} \mathrm{C}$-NMRspectrum of pure isolate compound

${ }^{1} \mathrm{H}-\mathrm{NMR}$ and ${ }^{13} \mathrm{C}-\mathrm{NMR}$ data showed that the isolate compound have 27 carbon atom, fourty six hydrogen and one oxygen, with structure shown in figure 18

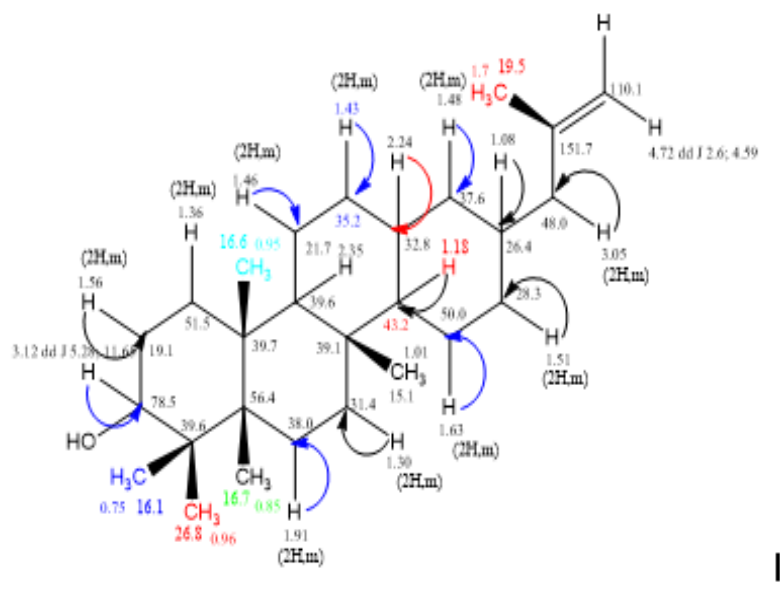

Fig 18. Structure terpenoid from $\mathrm{C}$ bicolor P.F Steven $\left(\mathrm{CDCl}_{3}\right)$ have antimalarial activity

\section{Conclusions}

1. These data showed the biological activity potency of Indonesian Clusiaceae plant (C. bicolor) as a source of antimalarial drugs and also showed that hexane and methanol fraction have antimalarial activity, but acetone fraction have not antimalarial activity, methanol fraction more active then hexane fraction,

2. According to the Figure 8 and 9, conclution that the sub fraction $\mathrm{MeOH} 7: 3$ is better as antimalarial compare to any another sub fraction.

3. Hemozoin crystal were detected by TEM after 24 hours incubation of parasite in extract sample.

4. One triterpen compound have isolated and have antimalarial activity with $\mathrm{IC}_{50}$ is $500 \mathrm{ppm}$

\section{Equations and mathematics}

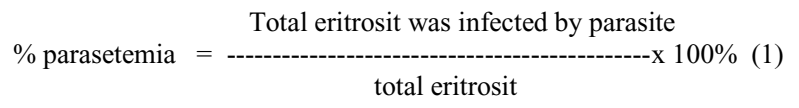

Percentase inhibition was obtained from parasetemia in control positive minus parasetemia in sampel /parasetemia in control x 100\% :

$$
\begin{gathered}
\text { Inhibisi= } \\
\text { Parasetemia ( in control - sample ) } \\
\text { Parasetemia in control positive }
\end{gathered}
$$

The authors are thankful to Ministry of Research Technology and Higher Education of the Repoblic of Indonesia through the scheme of Insentive Research Program for the National Innovation System (04/INS-2/PPK/E/E4/2017). for financial support and thank to LIPI for recording the 2 D NMR, thanks are also due to the Eijkman Insitute to detect the hemozoin crystal, and Mr Ismail Rahman from Hermatium - Researh Centre for Botani - LIPI for identification of sample.

\section{References}

1. Adebayo, J. O, and Krettl, A. U. Potential Antimalarials from Negerian plants: A reiview. Journal ethnopharmacologically, 113, 289-302 (2011). Collins, W. J., Greenhouse, B., , Rosenthal, P. J, and Dorsey G. The used of genotyping in antimalarial clinical trials: a systematic review of published studies from Malaria J., 5: 122, 1-8. (2011).

2. Silva, J. R de A., Ramos, A de S, Machado, M., Moura, D., Neto, Z., Cavalheiro., M. M. C., Fiqueiredo, V E do., Amaral, A. C F., Lopes, D. A Review of antimalarial plants used in traditional medicine in communities in Portuguese-Speaking countries: Brazil, Mozambique, Cape Verde, GuineaBissau, Sao Tome and Principe and Anggola. Mem Inst Oswaldo Crus, Rio de Janeiro, Vol 106, 142-158, (2011).

3. Ojha, P. K, and Roy, K., Chemometric modeling, docking and in silico design of triazolopyrimidinebased dihydroorotate dehydrogenase, European J. of Medicinal Chemistry, 45, 4645-4556.

4. Duffy R., Wade Cristine. Discovery of anticancer drugs from antimalarial natural products: a Medline literature review, Feature, 1359-6446/06/s. www. Drugdiscoverytoday.com. Vol 17 , no $17 / 18$, September (2012).

5. Li Jiazhong, Li. S., Bai, C., Liu, H., Gramatica, P. Structural requirements of 3-carboxyl-4(1H)quinolones as potential antimalarials from $2 \mathrm{D}$ and $3 \mathrm{D}$ QSAR analysis, J. of Molecular Graphics and Modelling. 44, 266-277. (2013).

6. Tames, A. P., Lantivt, D., Lim, E., Pezzuto, J. M., Chemosentizing action of cepharanthine against drug-resisitant human malaria, Plasmodium falciparum. J. of ethnopharmacoology, 98, 137-142. (2005).

7. Pouplin J N,Tran Hop, Tran Hung,Phan T A,Dolecek C, Farrar J, Tran T H, Caron P, Bodo B, Grellier P 
(2007). Antimalarial and cytotoxic activities of ethnopharma cologically selected medicinal plants from South Vietnam. .J. of Ethnopharma cology 109,p 417-427. (2010)

8. Sahal D.,Kannan and Chauhan, V.SApplying malaria parasite's heme detoxification system for screening potential antimalarial drugs. Analytical Biochemisy. 312, 258-260 (2003).

9. Ignatushchenko, M. V.. Winter, R.W., Bachinger, H. P., Hinrichs, D.V and Riscoe, M.K Xanthones as antimalarial agents : studies of a possible mode of action, FEBS letter 409, 67-73. (1997).

10. Geral, N., Mahajan B., and Kumar S., Mitosis in the Human malaria parasite Plasmodium falciparum, Eukaryotic Cell, Vol 10, no4, 474-481 (2011)

11. Brian. J, Ford C, J, Bradbury S, Transmission electron microscope (TEM). http://www.britania.com/technology/transmissionelectron-microscope

12. A. Jamilah. M, Hanafi, M., Artanti. N., Asih.P,B,A., and Syafruddin D, Antiplasmodial activity of hexane extract of Calophyllum Lowii. . J. of Tropical Medicinal Plants Vol 16 (Jan-Dec 2016) 